\title{
Control Change Cause Analysis-based Expressway Emergency Rescue Decision Approach
}

\author{
Ganggang Wu, Zongxiao Yang* and Lei Song \\ Institute of Systems Science and Engineering, Henan Engineering Laboratory of Wind Power Systems, \\ Henan University of Science and Technology, No.48 Xiyuan Road, Luoyang 471003, China \\ *Corresponding author
}

\begin{abstract}
Expressway is a zone of frequent occurrence of traffic accidents, and once accident happen, it will result in great economic losses and casualties, it is important to analyze the causes of the accidents timely and accurately, and what is more significant is formulating corresponding relief measures. Control change cause analysis (3CA) is a structured method that all events and consequences of an accident can be determined, and it is mainly used in related fields of safety management system. Applying 3CA in the expressway emergency rescue decision can analyze the cause of the accidentquickly and straightly, and thebarriers and controlsthat canprevent accidents from further development can be able tobe given meanwhile. Causes analyzed and barriers and controlsdetermined can be used tointegraterescue resources to minimize the lossestimely and quickly, whichhas a high practical value.
\end{abstract}

Keywords-control change cause analysis; structured method; expressway emergency rescue decision; barriers and controls

\section{INTRODUCTION}

So far,more than 80 countries or regions in the world have been in the use of the expressway[1]-[2], in which China's expressway mileage has reached 100000 kilometers, and become the longest all over the word,in additionit is rising at the speed of more than $10 \%$ a year in the comparison with the previous year. Expressway is the area of frequent occurrence of traffic accidents[3]-[4], and expressway mileage is rapidly growing,at the same time traffic accidents also are in rapid growth. For a long time, the expressway alwayshave traffic accidents all over the world, and these accidents have caused the people casualties and huge property losses[5]-[7].There is a big difference in the traffic on the expressway in time and space, so the probability of traffic accident is not the same in each section and different period on the expressway, which leads the relevant administrative departments ofexpresswayto have more huge challenge in making the decision of emergency rescue.

Expressway has its own particularity and there is a big difference between expressway and general road in the rescue of major accident. 3CA can be fast and efficient to analyze the cause of different accidents, and give the advice to reduce the influence of accident.Appling 3CA to expressway emergency rescue decision can quickly analyze the cause of the accident, and determinethe barriers and controlsof preventing the accident from taking place, thus can configure emergency resource reasonably, reduce the influence and losses of the accident when making the relief decisions, and put forward suggestions for the future safety management of the expressway [8]-[10].

\section{CONTROL Change CAUSE AnAlysis}

Control change cause analysis(3CA)has three different forms, Form-A, Form-B and Form-C[11].

\section{A. The Production and Development of 3CA}

3CA originated in a cooperative project run by the Humber Chemical Focus and the UK Health \&Safety Executive (HSE) in 2000.The project aimed to equip people with tools to help them investigate and identify lessons to be learned, and the project had produced an initial version of 3CA: the Form-A and its worksheet. During the period of 2007 to 2008, The Noordwijk Risk Initiative Foundation worked with UK Health \& Safety Executive to revisethe original 3CA materials; this work produced second version of 3CA: Form-B and its worksheet. In October 2009,the Noordwijk Risk Initiative Foundation introduced a graphic method to 3CA, and thisgraphical worksheet was designed to support the Form-B of 3CA.This form of 3CAbe designed as a training tool in the first place, as it proved effective in the field, and was written-up as a the Form-C of 3CA.

\section{B. The Main Steps of 3CA}

The main steps of 3CA here mainly accounts for the steps of Form-B, which is a more mature version of 3CA.

1) Preparation: Study all the information about the accident. As long as there is the fact about the accident can be used, the analysis is about to start.

2) Identify significant events: It can support this task using an appropriate sequencing method (e.g. STEP or ECFA+) to get a rigorous constructed sequence.

3) Identify barriers and controls: Use every significant event to statement barriers and controls that can prevent or reduce the effect of accident.

4) Prioritise significant events: Use whatever grading scheme fits the contextof your investigation to prioritize significant events.

5) State actual and expected behaviour: Analystcan applycontrastive statementto demonstrate the differences between actualand expected behavior, but judgmental 
expression is not allowed.Its expression form is that “[Actual:]+[Expected:] +[Standard:]”.

6) Explain the difference between (expected versus actual) in terms of 'original logic':“Original logic” is about the actor's thinking, motivation and assumptions associated with action when events were happening.Analyst need to explain why thebehavior of the actoris meaningful at that time.

7) Explain the difference between (expected versus actual) in terms of cultureand organisational issues: Cultural factors (e.g. dominant habits, attitudes, norms and local expectations); Organizationalissues (e.g. structure, leadership, politics, change, business difficulties, etc.).

8) Explain the difference between (expected versus actual) in terms of 'systems':Analyst need state why existing systems (or those which it is reasonable to expect in the context) allowed the difference between expected and actual behavior. If any data is missing, you should indicate this with a "?" and make an entry on your list of further enquiries. In this context, the word 'systems' refers to anyorganized set of activitiesdirected to the measurement and control of behavior, whether of people, things or conditions.

9) Review the analysis: Keep the 3CA open (live) until the end of the investigation. It is sure that remove as many "?" from the worksheet, as the facts emerging from the investigation allow; Identify any additional significant events from the new facts emerging from the investigation.Keep in mind that the "?" that you have entered into the worksheet are a valuable "deliverable" of theanalysis. The investigation will leave some questions unanswered.

\section{DESCRIPTION OF EXPRESSWAY ACCIDENTS}

\section{A. The Characteristics of Expressway Accidents}

Because of the characteristics of expresswaythathigh driving speed, the large flow of traffic, fully enclosed and soon, accidents on expressway often are mainly caused by collision, and scratches, rollover, rolling, fire, and crash form can also cause accidents.

Expressway accidents once occurs, it often causes dozens of cars even hundreds of collision of cars, resulting severe casualties and economic losses. Expressway accidents bring about road congestion and traffic jams, and make rescue equipment and personnel inaccessible to the scene of the accident, thus the rescue is harder.

\section{B. Common Illegal Behaviors in Expressway}

There are 10 kinds of common illegal behaviors in expresswayand all of these behaviors can bring about accidents easily.

These illegal behaviors are:(1)overspeed, (2) fatigue driving, (3)overtaking on emergency driving lane, (4)triangle warning is not placed in Emergency driving lane or not placed according to stipulations, (5)slow cars occupy fast traffic lane, and overtake on the right, (6)change lane not opening turn light, (7)not having reasonable driving distance, (8)parking on entry or exist, (9)reverse in exist, and (10)drivers don't open the car light when enter into cave in the rain and snow days.

\section{ANALYSIS FOR EXPRESSWAY ACCIDENTS}

\section{A. The Descpription of the Case}

OnMay 29, 2013, there is a very fatal traffic accident on the expressway from Guiyang to Duyun in China, which caused collision of eight cars, and two people died and one person wounded seriously and there are many people suffered slightly injured. Although this accident is very serious, in the accident,the owner of a FOCUS turnedthe steering wheel at the time of his car was being collided, thus saved the whole family.

Because it rainedall the day, there were many small accidents on the expressway, and the road traffic jams were always happened. When a car of FOCUS was traveling to a tunnel with a steep slope, it met a big traffic jam, so the driver had to stop the car on the expressway to wait for the recovery of the traffic. At that moment the accident happened which a speeding big trucks hit the FOCUS and the FOCUS was hit to the side of the road, and then the big trucks continued crashing into a BMW X3, and before the big trucks stopped, it with the BMW X3 hit a POLO parking on the road. This is the main process of the accident and ultimately the main driver and copilot of double-box POLO both died, and the tail of the car was completely out of its shape, and the roof was extrusion collapse.BMW X3 is bumped into discus, and fortunately the driver survived.

\section{B. Control Change Cause Analysis of the Case Above}

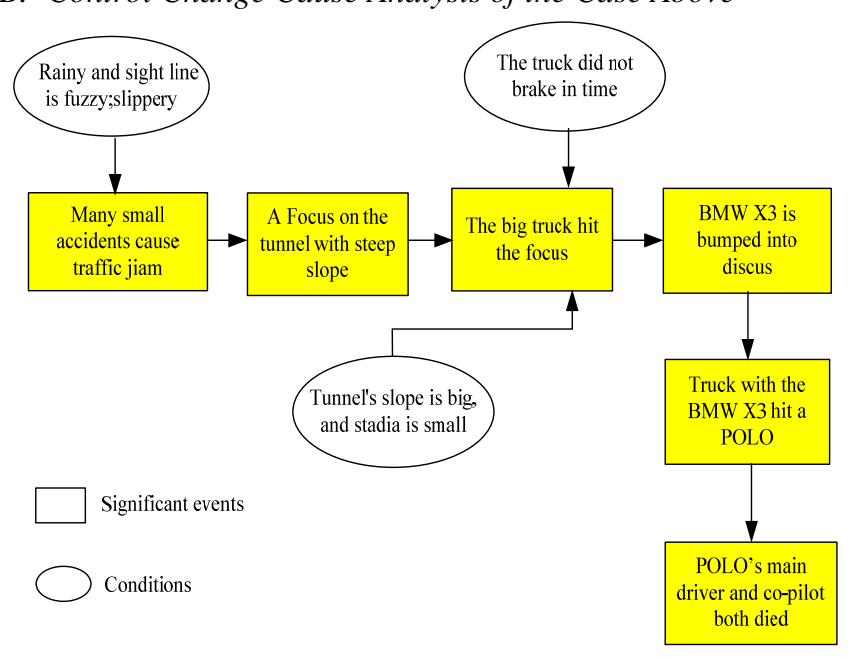

FIGURE I. FIGURE I.ECFA+ OF ACCIDENT

3CA is a method that it needs some different methods to fulfill the worksheet, and the ECFA+(Events and Conditional Factors analysis; it is different from Events and Casual factors Charting and Analysis(ECFA)) is the most important way in these methods. ECFA+ is a means which produces an account of an incident from the existing evidence. The first part of 3CAis that analyst use the method of ECFA+ to identify the significant events and conditions according to the accident sequence, 3CA can find out the causes by analyzing these significant events and conditions. To the accident above, sorting result is shown in Figure I. The yellow box in the figure 
is the significantevents in the accident, and the white oval represents the conditions of significant events. In the process of 3CA, significant events must be analyzed, and in order to reduce the workload, some conditions are not necessary to be analyzed, and the three conditions are unnecessary to be analyzedin Figure I.

The main process of 3CA is to structure inquiries into the reasons underlying these significant events, and they canincrease the risk of unwanted events that might followmarkedly. After the significant events are identified, analyst can start to conduct the substantial part of 3CA and the worksheet is used to analyze the accident. For the three versions of 3CA, Form- $B$ is a more mature method compared to Form- $A$, and it is a more concise compared to Form- $C$ because Form- $C$ is a complicated graphical approach. Here Form- $B$ was applied in Table I, the steps of Form- $B$ have been presented before.

TABLE I. 3CAOFTHE ACCIDENT

\begin{tabular}{|c|c|c|c|}
\hline $\begin{array}{c}\text { (1) } \\
\text { Significant events }\end{array}$ & $\begin{array}{c}(2) \\
\text { Safety Barriers \& } \\
\text { Work Controls } \\
\end{array}$ & $\begin{array}{l}\text { (3) } \\
\text { Priority for } \\
\text { analysis }\end{array}$ & $\begin{array}{c}\text { (4) } \\
\begin{array}{c}\text { Difference between situation in accident/ incident and } \\
\text { expectations in (2) }\end{array}\end{array}$ \\
\hline Several smallaccidents & $\begin{array}{l}\text { Small accidents } \\
\text { Should be handled } \\
\text { in time }\end{array}$ & 3 & $\begin{array}{l}\text { Actual: Small accident was not handled in time and the traffic jam } \\
\text { happened } \\
\text { Expected: Accident was handled timely and recover the traffic } \\
\text { Standard:Rules of traffic accident handling procedure }\end{array}$ \\
\hline $\begin{array}{l}\text { A FOCUS on thetunnel with } \\
\text { steep slope }\end{array}$ & No accident ahead & 2 & $\begin{array}{l}\text { Actual: FOCUS stopped on the tunnel slope } \\
\text { Expected: Parking safely } \\
\text { Standard: No parking at the exit of tunnel }\end{array}$ \\
\hline The big truck hit the FOCUS & $\begin{array}{l}\text { On bad Weather, } \\
\text { the cars should go slow at } \\
\text { tunnel portal }\end{array}$ & 1 & $\begin{array}{l}\text { Actual: Truck hit FOCUS to the side of road } \\
\text { Expected: Trucks should stop at first time } \\
\text { Standard: Traffic rules }\end{array}$ \\
\hline $\begin{array}{l}\text { BMW X3 is bumped into } \\
\text { discus }\end{array}$ & $\begin{array}{l}\text { Brake in time, and try to } \\
\text { avoid traffic and people }\end{array}$ & 4 & $\begin{array}{l}\text { Actual: BMW X3 was crashed into a discus by truck } \\
\text { Expected: Truck stop in time } \\
\text { Standard: Traffic rules }\end{array}$ \\
\hline $\begin{array}{l}\text { Truck with theBMW X3 hit a } \\
\text { POLO }\end{array}$ & $\begin{array}{l}\text { On bad weather,the cars } \\
\text { should go slow at the } \\
\text { tunnel portal }\end{array}$ & 5 & $\begin{array}{l}\text { Actual: Truck hit the vehicles ahead sequentially } \\
\text { Expected: Truck can stop } \\
\text { Standard: Traffic rules }\end{array}$ \\
\hline $\begin{array}{l}\text { POLO's two drivers both } \\
\text { died }\end{array}$ & $\begin{array}{l}\text { The security system of } \\
\text { POLO car should be open }\end{array}$ & 6 & $\begin{array}{l}\text { Actual: POLO's main driver and co-pilot both died } \\
\text { Expected: All of people in the car are safety }\end{array}$ \\
\hline
\end{tabular}

\begin{tabular}{|c|c|c|}
\hline \multicolumn{3}{|c|}{ (5)The difference between the observed and expected behavior is because... } \\
\hline (5a)“Original logic” & $\begin{array}{l}\text { (5b)Organizational } \\
\text { \& Cultural Factors }\end{array}$ & (5c)Systems \\
\hline $\begin{array}{l}\text { Traffic administration didn't find and handle } \\
\text { accidents; } \\
\text { Part of the drivers didn't comply with the order } \\
\text { which led the traffic jams }\end{array}$ & $\begin{array}{l}\text { Traffic administration sent police to the } \\
\text { scene only after received } \\
\text { alarminformation;Part of drivers didnot } \\
\text { drive in order }\end{array}$ & $\begin{array}{l}\text { The management department didn't make the road } \\
\text { risk assessment intime and start on a small accident } \\
\text { emergency system }\end{array}$ \\
\hline $\begin{array}{l}\text { The owner of FOCUSstopped driving because } \\
\text { of traffic jam }\end{array}$ & $\begin{array}{l}\text { The drivers of rear cars would see the } \\
\text { vehicle parked, and braked in time }\end{array}$ & $\begin{array}{l}\text { The owner of FOCUS didn't realize the hidden } \\
\text { trouble when he stopped the car in that case }\end{array}$ \\
\hline $\begin{array}{l}\text { Truck driver did not stop his vehicle; parking } \\
\text { system of truck failed }\end{array}$ & Truck drivers often drive fast & \multirow{2}{*}{$\begin{array}{l}\text { Parking system of truck failed;the driver of FOCUS } \\
\text { didn't pay attention to the status of rear vehicles, } \\
\text { and didn't dodge accurately and timely }\end{array}$} \\
\hline Truck drivers didn't recognize hitting BMW & $\begin{array}{l}\text { Truck's speed was too high and its inertia } \\
\text { was big }\end{array}$ & \\
\hline $\begin{array}{l}\text { The brake system of truck failed;the POLO's } \\
\text { driverdidn't pay attention to the situation back }\end{array}$ & $\begin{array}{l}\text { The driver of POLO did not have the habit } \\
\text { of observing the situation back }\end{array}$ & $\begin{array}{l}\text { The driver of POLO failed to transform their way of } \\
\text { parking timely, and didn't avoid the truck } \\
\text { initiatively and timely }\end{array}$ \\
\hline $\begin{array}{l}\text { People in the car did } \\
\text { not turn on safety system }\end{array}$ & People didn’t have the self-saving awareness & The safety performance of POLO is too pool \\
\hline
\end{tabular}

Use the steps of Form-B and the analysis of the most significant event that "The big truck hit the FOCUS" to illustrate the establishment process of TABLE I. According to the steps of 3CA, after the significant event that "The big truck hit the FOCUS" is identified, the second step is to identify the barriers and controls that preventing the event from happening: in the case of FOCUS was parking on tunnel with steep slope, it is necessary that "On bad weather, the cars should go slow at the tunnel portal" to make that the big truck didn't hit the
FOCUS; The third step is to identify the priority of significant events: "The truck hit the FOCUS" is the beginning of the accident, if the event didn't happen, all subsequent events would not exist, so it is the most priority to consider, namely the third column fill in " 1 "; The fourth step is to clarify the actual situation and expectations: obviously, "The big truck hit the FOCUS" is the actual situation, and the expectation is certainly "The big truck should stop at first time" that the accident would not have happened; For original logic: it is 
"Truck driver did not stop his vehicle; parking system of truck failed" that make the driver of truck consider that it is right to do like that; The culture and organizational factors: the driving habits of truck driver can be used to explain the situation, and it is likely that "Truck drivers often drive fast" caused the occurrence of this event; In the last column, the system include anybody, anythingand the environmental conditions in the event: it is a very important point that "Parking system of truck failed"led to truck cannot stop in time and cause the occurrence of the actual situation, the "The driver of FOCUS didn't pay attention to the status of rear vehicles, and didn't dodge accurately and timely" is also one of the reasons.

For the method of Form-B of 3CA, all the events of the accident must be described with a model of ECFA+, namely the fig.1, and then fill out table 1 completely. In the analysis, we can notice that the accident occurrence was because that the weather made the FOCUS stopping in the tunnel firstly, and it is also the weather what caused the driver of trucks failed to find the FOCUS parking in the tunnel portal and braked in time. The reason of weather is that we cannot overcome, but the early warning measures should be the responsibility of the management department of expressway in bad weather environment. At the beginning, several small accidents were not handled in time, and the management department did not turn on the emergency system of small accidents, which was the fundamental cause of the accident, and these departments need improve their work. In bad weather conditions, the truck's driver regardless of the weather and the stopped vehicle turning on emergency lights on the road and continued to move quickly and led to the accident, and this is the fuse of the accident, and it is also one of the root causes of the accident.

\section{CONCLUDING REMARKS}

Because that the causes of expressway traffic accidents are generally multilevel complex combination, and the accident need to be handled quickly after it happened, for this, it is necessary to choose a strict structured way, and this way can be learnt quickly. 3CA is a method that it is suitable to the root causes of traffic accidents and injuries or property losses, and corresponding controls and barriers to reduce the probability of occurrence before the accident happened and the impact after the accident happened, which can reach the demands of validity and timeliness of expressway emergency rescue decision, and also meet the requirements of the accuracy and efficiency of expressway emergency plan.

3CA can be used to analyze any expressway accidents for the root cause including human errors, vehicle faults, unreasonable planning of the facilities along the road, management loopholes, wicked weathers and so on.

After the expressway accidents happened, it is capable to use 3CA to analyze an accident for the level of events. Like this, it makes rescue resources reasonable configuration, and the rescuer can integrate the rescue force timely and quickly and reduce the casualties, property losses, and social impact to a minimum.

Apply 3CA to the case of accidents happened in the past, analyst can find drawbacks and the loopholes in the emergency rescue system, and the process of analysis can identify the corresponding barriers and controls and reach a standard solution to prevent similar accident from happening again.

\section{ACKNOWLEDGMENT}

The financial supports from the National Natural Science Foundation of China (NSFC) under the grant No.70671035 and No.71071078 are acknowledged gratefully. The authors also gratefully acknowledge the helpful comments and suggestions of the reviewers, which have improved the presentation.

\section{REFERENCES}

[1] D. Alvear, O. Abreu. Decision support system for emergency management: road tunnels. Tunnelling and underground space technology, Vol.34, 2013, pp.13-21.

[2] C. C. Li, Z. J. Bao. Expressway safety management system under adverse weather. Proceedings of the Conference on Traffic and Transportation Studies, ICTTS, Vol.322, 2008, pp.988-995.

[3] W.Liu, Y.Y.Huang. Emergency rescue system for expressway traffic accidents. 3rd International Conference on Transportation Engineering, 2011, pp.3177-3182.

[4] L. Song, Z. X. Yang, R. T. Deng. Research on chain of events in expressway emergency rescue behavior. International Conference on Social, Education and Management Engineering (SEME), 2014, pp.8488.

[5] H.Chen, Y.S. You, A Capacity Assessment Method on Urban Expressway after Traffic Incident. Procedia - Social and Behavioral Sciences, Vol.96, 2013, pp.1921-1928.

[6] Y.M. Chen, D.Y.Xiao. Emergency Evacuation Model and Algorithms. Journal of Transportation Systems Engineering and Information Technology, Vol.8, 2008, pp.96-100.

[7] B.Yang, J.B.Zhou. Effectiveness of Traffic Sign Setting in Adjacent Tunnel Exit. Procedia - Social and Behavioral Sciences, Vol.96, 2013, pp.5-11.

[8] G. Nano, M. Derudi. A critical analysis of techniques for the reconstruction of workers accidents. Chemical engineering transactions, Vol.31, 2013, pp. 415-420.

[9] G. Nano, M. Derudi. Evaluation of workers accidents through risk analysis. Chemical engineering transactions, Vol.26, 2012, pp. 495-500.

[10] J. D.Zhao, X.Z.Chen. Study on demand forecasting and allocation of expressway emergencyvehicle resource. Journal of Computational Information Systems, Vol.10, 2014, pp.4205-4215.

[11] M. Gerbec. Supporting organizational learning by comparing activities and outcomes of the safety-management system. Journal of Loss Prevention in the Process Industries, Vol.26, 2013, pp.1113-1127. 